IZA DP No. 8535

Measurement Error in Subjective Expectations and the Empirical Content of Economic Models

Tilman Drerup

Benjamin Enke

Hans-Martin von Gaudecker

October 2014 


\title{
Measurement Error in Subjective Expectations and the Empirical Content of Economic Models
}

\author{
Tilman Drerup \\ University of Bonn \\ Benjamin Enke \\ University of Bonn \\ Hans-Martin von Gaudecker \\ University of Bonn \\ and IZA \\ Discussion Paper No. 8535 \\ October 2014 \\ IZA \\ P.O. Box 7240 \\ 53072 Bonn \\ Germany \\ Phone: +49-228-3894-0 \\ Fax: +49-228-3894-180 \\ E-mail: iza@iza.org
}

\begin{abstract}
Any opinions expressed here are those of the author(s) and not those of IZA. Research published in this series may include views on policy, but the institute itself takes no institutional policy positions. The IZA research network is committed to the IZA Guiding Principles of Research Integrity.

The Institute for the Study of Labor (IZA) in Bonn is a local and virtual international research center and a place of communication between science, politics and business. IZA is an independent nonprofit organization supported by Deutsche Post Foundation. The center is associated with the University of Bonn and offers a stimulating research environment through its international network, workshops and conferences, data service, project support, research visits and doctoral program. IZA engages in (i) original and internationally competitive research in all fields of labor economics, (ii) development of policy concepts, and (iii) dissemination of research results and concepts to the interested public.
\end{abstract}

IZA Discussion Papers often represent preliminary work and are circulated to encourage discussion. Citation of such a paper should account for its provisional character. A revised version may be available directly from the author. 


\section{ABSTRACT}

\section{Measurement Error in Subjective Expectations and the Empirical Content of Economic Models}

While stock market expectations are among the most important primitives of portfolio choice models, their measurement has proved challenging for some respondents. We argue that the magnitude of measurement error in subjective expectations can be used as an indicator of the degree to which economic models of portfolio choice provide an adequate representation of individual decision processes. In order to explore this conjecture empirically, we estimate a semiparametric double index model on a dataset specifically collected for this purpose. Stock market participation reacts strongly to changes in model parameters for respondents at the lower end of the measurement error distribution; these effects are much less pronounced for individuals at the upper end. Our findings indicate that measurement error in subjective expectations provides useful information to uncover heterogeneity in choice behavior.

JEL Classification: C35, C51, G11

Keywords: measurement error, subjective expectations, stock market participation

Corresponding author:

Hans-Martin von Gaudecker

University of Bonn

Department of Economics

Adenauerallee 24-42

53113 Bonn

Germany

E-mail: hmgaudecker@uni-bonn.de

\footnotetext{
* We would like to thank the team of CentERdata, especially Miquelle Marchand, for their help in the data collection process, Philipp Kloke and Lukas Wendlik for able research assistance, Bas van Heiningen for help in recording the introductory screencast, as well as Jürgen Maurer for sharing and explaining the code used in Maurer, Klein, and Vella (2010) that forms the basis of ours.
} 


\section{Introduction}

Stock market expectations are among the most important primitives of economic models of portfolio choice, but measurement error is pervasive in subjective beliefs data. For example, many empirical studies have discarded large fractions of data because answers do not obey the laws of probability (Manski 2004; Hurd, Rooij, and Winter 2011). The semantics of measurement error in subjective expectations data, however, is potentially quite different from contexts in which measurement error is usually studied, such as past income, savings, or consumption. In the latter cases, there is a precisely defined "true" value and measurement error arises because of imperfect recall (Hoderlein and Winter 2010) or incongruent variable definitions.

In case of subjective expectations, however, analysts may be chasing an elusive target: It is not evident that all people hold well-formed beliefs about a given phenomenon. For example, the prevalence of 50-50 responses in expectations surveys has been interpreted in exactly this way by Bruine de Bruin, Fischhoff, et al. (2000) or Bruine de Bruin and Carman (2012). In consequence, key structural parameters of economic models might not be present in the form envisioned by the econometrician (Stiglitz 2002; Rust 2014). If this is the case, standard techniques of using a corrected estimate instead of the misreported values (Wansbeek and Meijer 2000; Schennach 2013) will not lead to improved estimates of choice models because the corrected estimate does not form the basis of decisions, either. In this paper, we take a very different route and use the extent of measurement error to uncover heterogeneity in choice behavior. Put differently, we argue that the magnitude of measurement error in stated beliefs should provide insights into the extent to which an economic model constitutes an adequate description of individuals' portfolio choice behavior.

To explore this channel and motivate our empirical strategy, Section 2.1 presents a simple economic model of stock market participation that clarifies the roles of expectations, preferences, and transaction costs. In Section 2.2, we argue that for a variety of alternative decision modes - trusting others' advice or following rules of thumb, among others - individuals need not hold particularly meaningful beliefs about the future evolution of the stock market. Consequently, the data for individuals who entertain such choice rules will be characterized by two features. First, their stated beliefs will be prone to measurement error; second, the sensitivity 
of their stockholdings to changes in model primitives will be low. In order to empirically evaluate this hypothesis, we propose to estimate a Klein and Vella (2009) semiparametric double index model. In this model, the first index contains the primitives of our theoretical model (such as beliefs and preferences), while the second index includes quantitative and qualitative indicators of measurement error. Both indices may interact in a fully nonparametric fashion to obtain predicted stockholding probabilities.

Section 3 describes the dataset that we collected specifically for this study. Section 4 presents the results of our empirical application. We demonstrate that changes in primitives of the economic model induce large variation in stock market participation if the measurement error index is low. If measurement error is high, the effect of changes in beliefs and preferences on stockholdings is much smaller. We perform a number of variations on this theme and show that the results hold up in several different specifications. We then demonstrate the usefulness of our modeling approach for the analysis of less detailed data by estimating a specification with variables that are commonly available or inexpensive to collect. In particular, we show that restricting ourselves to a simple measure of expectations and purely qualitative measurement error proxies yields a similar overall pattern. As one would expect, the differences along the measurement error distribution are less pronounced. We discuss our results and conclude in Section 5.

\section{Motivation and Empirical Strategy}

We develop our econometric strategy in three steps. First, we characterize a household's portfolio problem by means of a simple choice model. We then explain in detail why we conjecture that the degree to which this model serves as an adequate description of the decision-making process varies across households and why we expect that variation in measurement error can be exploited to capture this adequacy. In the third step, we present our econometric strategy that implements these ideas.

\subsection{A Simple Economic Model of Stock Market Participation}

In our description of a household's portfolio choice problem we follow Campbell and Viceira (2002). We assume that the household maximizes a power utility function defined over next 
period's expected financial wealth $E_{t}\left[W_{t+1}\right]$ by allocating fractions of period- $t$ wealth to one safe and one risky asset. If the household can neither short the risky asset nor leverage his position in it, the optimal risky asset share $\theta^{\text {opt }}$ solves:

$$
\theta^{\text {opt }}=\underset{\theta}{\arg \max }\left\{\frac{E_{t}\left[W_{t+1}(\theta)^{1-\gamma}\right]}{1-\gamma}\right\} \quad \text { s.t. } \quad 0 \leq \theta \leq 1
$$

Risk aversion and a household's beliefs about the returns of the two assets determine the optimal decision. Denote a household's expected return for the safe asset by $\mu_{t+1}^{\text {safe }}$ and assume that the household's expectations for the risky asset's return can be described by a log-normal distribution with mean $\mu_{t+1}^{\text {risky }}$ and standard deviation $\sigma_{t+1}^{\text {risky }}$. When returns are log-normally distributed, so is $W_{t+1}$. For a $\log$-normal variable it holds that $\log E[X]=E[\log X]+$ $1 / 2 \operatorname{Var}[\log X]$. Thus, the maximization problem can be rewritten as:

$$
\theta^{\mathrm{opt}}=\underset{\theta}{\arg \max }\left\{(1-\gamma) E_{t}\left[w_{t+1}(\theta)\right]+\frac{1}{2}(1-\gamma)^{2} \operatorname{Var}_{t}\left[w_{t+1}(\theta)\right]\right\} \quad \text { s.t. } \quad 0 \leq \theta \leq 1
$$

where lower case letters are logarithms. Using a first-order Taylor series approximation, next period's log wealth can be written as:

$$
w_{t+1}(\theta)=w_{t}+(1-\theta) \mu_{t+1}^{\text {safe }}+\theta \mu_{t+1}^{\text {risky }}+\frac{1}{2} \theta(1-\theta)\left(\sigma_{t+1}^{\text {risky }}\right)^{2}
$$

Substituting this into the expression for $\theta^{\text {opt }}$ and dividing by $1-\gamma$, we obtain for the maximand:

$$
w_{t}+\theta\left(\mu_{t+1}^{\text {risky }}-\mu_{t+1}^{\text {safe }}\right)+\frac{1}{2} \theta(1-\gamma \theta)\left(\sigma_{t+1}^{\text {risky }}\right)^{2}
$$

Solving the first-order condition of this problem for the optimal share $\theta^{\text {opt }}$ yields:

$$
\theta^{\mathrm{opt}}=\frac{\mu_{t+1}^{\text {risky }}-\mu_{t+1}^{\mathrm{safe}}+\frac{1}{2}\left(\sigma_{t+1}^{\text {risky }}\right)^{2}}{\gamma\left(\sigma_{t+1}^{\text {risky }}\right)^{2}}
$$

At plausible parameter values of $\gamma$, the optimal risky asset share will be positive when historical return data are used to estimate $\mu^{\text {safe }}, \mu^{\text {risky }}$, and $\sigma^{\text {risky }}$ as proxies of households' expectations. However, studies on stock ownership find that a large fraction of the population does not participate in the stock market (e.g., Haliassos and Bertaut 1995). Arguably the most promi- 
nent explanation for why households abstain from participation is the existence of (broadly defined) transaction costs (Vissing-Jørgensen 2002). These transaction costs are likely to vary with household characteristics. If participation comes with fixed monetary costs, for example, wealthy households will be more likely to invest in risky assets, since for them the fixed costs are spread over larger investments. If information costs play an important role, transaction costs will be lower for numerate respondents who are quicker to grasp the basic functioning of the stock market. We assume that the variables affecting transaction costs can be modeled by observable household characteristics $X^{\text {ta }}$; denote the resulting transaction costs by $f\left(X^{\text {ta }}\right)$. We now combine the optimal risky asset share (1), transaction costs, and random influences $\varepsilon$ in a simple random utility model of stock market participation:

$$
Y \equiv \mathbf{I}\{\theta>0\}= \begin{cases}1 & \text { if } \theta^{\text {opt }}\left(\mu_{t+1}^{\text {risky }}-\mu_{t+1}^{\text {safe }}, \sigma_{t+1}^{\text {risky }}, \gamma\right)-f\left(X^{\mathrm{ta}}\right)>\varepsilon \\ 0 & \text { otherwise }\end{cases}
$$

According to (2), the probability of participating in the stock market will depend on the mean and variance of beliefs over the risky asset, the expected risk-free rate, risk aversion, variables proxying transaction costs, and the stochastic properties of $\varepsilon$. If the latter was normally distributed, one could estimate (2) by means of a standard Probit model. Estimators that make minimal distributional assumptions but enable the researcher to recover marginal effects still require $\varepsilon$ to either be homoskedastic or have a very particular form of heteroskedasticity (Klein and Vella 2009). If our conjecture about a varying explanatory content of $\theta^{\text {opt }}-f\left(X^{\text {ta }}\right)$ is correct, this will be reflected in a form of heteroskedasticity that violates these assumptions. In particular, the variance of $\varepsilon$ will vary with measurement error in a form that is unknown a priori.

\subsection{Putting Measurement Error in Subjective Beliefs to Productive Use}

The model combines effortful reasoning about future states of the world with personal risk tolerance to form a choice rule. While such behavior is at the heart of economic thinking, there are a number of reasons why the explanatory content of this model is likely to vary in the population. For example, almost half of the Dutch population report that they mostly rely on the advice of family, friends, or professionals when it comes to important financial 
decisions (Gaudecker forthcoming). Individuals may take decisions intuitively (Kahneman 2011; Binswanger and Salm 2013) or follow simple rules of thumb like holding an equity share of 100 minus age (see, e.g., the discussion in Ameriks and Zeldes 2004).

However, if some households base their investment decisions on such alternatives, then they have less incentives to maintain a meaningful, up-to-date, and/or reasonably stable belief about the evolution of the stock market. This should have at least two sets of consequences. First, different methods to elicit beliefs should lead to divergent reports, self-expressed confidence in one's estimates should decrease, and one should find tasks related to belief elicitation rather difficult: Measurement error in subjective beliefs is high. Second, the marginal effects of changes in beliefs on portfolio choice behavior should be much smaller than for individuals whose choice behavior is well approximated by the economic model. Thus, the magnitude of measurement error in beliefs is informative about economic quantities of interest.

There is a vast literature on measurement issues in subjective expectations of stock market developments. Manski (2004) and Hurd (2009) provide excellent overviews. First-order evidence for measurement error is provided by the facts that many answers to probabilistic survey questions violate basic laws of probability and that non-response tends to be concentrated among sub-groups who do not follow the stock market development (Hurd 2009). In addition, consistent with our interpretation of measurement error as reflecting the absence of meaningful expectations, several authors argue that the prevalence of 50-50 responses to probability questions (Manski 2004; Hurd 2009; Kleinjans and Soest 2014) reflects epistemic uncertainty rather than a genuine belief (Bruine de Bruin, Fischhoff, et al. 2000). Such an interpretation has been backed by explicit follow-up questions (Hurd 2009; Bruine de Bruin and Carman 2012; Binswanger and Salm 2013).

Similar patterns of imprecise measurements have been documented for risk preferences. Gaudecker, Soest, and Wengström (2011) and Choi et al. (2014) show that for respondents with high socio-economic status, sequences of lottery decisions are much more consistent with flexible parametric utility functions and the generalized axiom of revealed preferences, respectively. Put differently, risk preference parameters are much more precisely measured for these subgroups.

In sum, different pieces of evidence suggest that subjective stock market beliefs are measured with error and that such error-laden responses provide information about the meaningfulness 
of the underlying belief distribution. To the extent that the absence of meaningful beliefs is associated with the use of alternative choice rules, information on measurement error can be exploited to evaluate the explanatory content of the simple model of stock market participation discussed above.

\subsection{Econometric Specification}

In econometric terms, a consequence of measurement error is that $\varepsilon$ in (2) will be heteroskedastic, i.e., its variance will increase in the amount of measurement error. Depending on the precise decision-making process, it may also have group-specific means different from zero. For example, the most prevalent advice by family and friends seems to be non-participation in the stock market (Gaudecker forthcoming). For the group of individuals who follow this advice, participation rates will be low even if $\theta^{\text {opt }}-f\left(X^{\text {ta }}\right)$ takes on positive values on average. In order to capture these consequences, we require an econometric specification where the predictions of the choice model (2) interact with the extent of measurement error in a flexible way. The double index binary choice model of Klein and Vella (2009) is ideally suited for the structure of our problem. The model obtains an estimate of the probability of stock market participation by nonparametrically combining two linear indices.

We first aggregate $\mu_{t+1}^{\text {risky }}-\mu_{t+1}^{\text {safe }}, \sigma_{t+1}^{\text {risky }}, \gamma$, and $X^{\text {ta }}$ into one vector $X^{\text {mod }} ; X^{\text {mod }} \beta^{\text {mod }}$ approximates our choice model from 2.1. ${ }^{1}$ We will refer to $X^{\bmod } \beta^{\text {mod }}$ as the economic model index in what follows. In a second vector $X^{\text {me }}$, we group quantitative and qualitative indicators of measurement error as well as covariates that we would expect to influence the "propensity to use economic reasoning"; the latter may overlap with covariates included in the economic model index to proxy transaction costs. Accordingly, we refer to $X^{\text {me }} \beta^{\text {me }}$ as the measurement error index. The Klein and Vella (2009) estimator models the relationship of both indices and

\footnotetext{
${ }^{1}$ We also experimented with calculating $(1)$ and including it alongside $X^{\text {ta }}$. This led to numerical difficulties as the covariance matrix of the two indices was near-singular for a wide range of parameter values. We attribute this to the lack of a quantitatively meaningful measure of $\gamma$ (Rabin 2000) and to a fat right tail of $\left(\sigma_{t+1}^{\text {risky }}\right)^{2}$. The latter is likely responsible for the numerical problems; it is also the reason why we use the standard deviation of beliefs instead of the variance.
} 
risky asset holdings as: ${ }^{2}$

$$
P\left(Y=1 \mid X^{\mathrm{mod}} \beta^{\mathrm{mod}}, X^{\mathrm{me}} \beta^{\mathrm{me}}\right)=h\left(X^{\mathrm{mod}} \beta^{\mathrm{mod}}, X^{\mathrm{me}} \beta^{\mathrm{me}}\right)
$$

This structure is directly related to (2) in that the measurement index further parameterizes $\varepsilon$, i.e., the random component is systematic to some extent. The function $h(\cdot, \cdot)$ provides a nonparametric link mapping the indices for the economic model and measurement error into stock market participation probabilities.

To attain identification (up to location and scale) of the parameters $\beta^{\text {mod }}$ and $\beta^{\text {me }}$, we require that at least one continuous variable per index is excluded from the other index. We normalize the coefficients on one of these variables per index to one. The resulting model satisfies the form in A5 of Klein and Vella (2009) without requiring reparameterization. Under assumptions given in Klein and Vella (2009)-mainly smoothness of $h(\cdot, \cdot)$ and compact support of the covariates - the probability to participate in the stock market can be expressed as a function of the densities conditional on participation:

$$
P\left(Y=1 \mid X^{\bmod } \beta^{\text {mod }}, X^{\mathrm{me}} \beta^{\mathrm{me}}\right)=\frac{f_{Y=1}\left(X^{\mathrm{mod}} \beta^{\mathrm{mod}}, X^{\mathrm{me}} \beta^{\mathrm{me}}\right) \cdot P(Y=1)}{f\left(X^{\mathrm{mod}} \beta^{\mathrm{mod}}, X^{\mathrm{me}} \beta^{\mathrm{me}}\right)},
$$

where $f(\cdot)$ denotes the unconditional density of the bivariate index and $f_{Y=1}(\cdot)$ its density conditional on participation in the stock market. Kernel density estimators for these quantities are obtained under a multi-stage local smoothing procedure to achieve a sufficiently low order of the bias. Denoting the resulting estimator for (4) as $\hat{P}_{i}\left(\beta^{\text {mod }}, \beta^{\text {me }}\right)$, we can write the semiparametric maximum likelihood estimator for $\beta^{\text {mod }}, \beta^{\text {me }}$ as:

$$
\left(\hat{\beta}_{\mathrm{ml}}^{\mathrm{mod}}, \hat{\beta}_{\mathrm{ml}}^{\mathrm{me}}\right)=\underset{\beta^{\text {mod }}, \beta^{\mathrm{me}}}{\arg \max } \sum_{i=1}^{N} \hat{\tau}_{i}\left[Y_{i} \cdot \log \hat{P}_{i}\left(\beta^{\mathrm{mod}}, \beta^{\mathrm{me}}\right)+\left(1-Y_{i}\right) \cdot \log \left(1-\hat{P}_{i}\left(\beta^{\mathrm{mod}}, \beta^{\mathrm{me}}\right)\right)\right],
$$

where $\hat{\tau}_{i}$ denotes a smooth trimming function ensuring that densities do not become too small (Klein and Spady 1993). Klein and Vella (2009) show that $\left(\hat{\beta}_{\mathrm{ml}}^{\mathrm{mod}}, \hat{\beta}_{\mathrm{ml}}^{\mathrm{me}}\right)$ converges at rate $\sqrt{N}$ to its true value. While the parameter values do not allow for a direct interpretation, various quantities of interest like average partial effects can be computed with little effort.

\footnotetext{
${ }^{2}$ Klein and Vella (2009) frame their discussion in terms of an estimator for a single-equation binary response model with dummy endogenous variable when no instruments are present. A first application that applies it directly to two indices is given in Maurer (2009).
} 
In sum, our empirical model allows for a flexible interplay between traditional economic parameters and measurement error proxies in generating choice behavior. In particular, it will allow an analysis of how marginal changes in model parameters translate into stock market participation, and how this relationship varies across respondents with differential degrees of measurement error.

\section{$3 \quad$ Data and Descriptive Statistics}

Our data stem from the Dutch LISS study (Longitudinal Internet Studies for the Social Sciences), which regularly administers Internet surveys and experiments to a panel of households comprising a probability sample drawn from the population register kept by Statistics Netherlands.

Implementing our empirical strategy requires data on individual stock market participation, subjective beliefs and risk aversion, proxies for the degree of measurement error in individual responses, and a rich set of sociodemographic covariates. Only the latter are present in the LISS panel by default. In order to obtain measures for the main quantities of interest, we implemented a series of incentivized experiments and survey questions in August and September of 2013. We restricted our experiments to households with financial wealth in excess of $1,000 €$ to focus on respondents with substantial incentives to think about portfolio allocations. To increase turnout, we also included individuals who refused to answer questions about their exact amount of wealth. Within households, we selected the financial decision maker. In total, 2,125 individuals completed both survey waves. After dropping observations with missing data, we are left with a final sample of 2,072 observations.

\subsection{Outcome Variable: Stock Market Participation}

LISS routinely collects detailed data on respondents' financial background, including information on asset ownership. To ensure the relevance of elicited beliefs for current portfolio allocations, we asked respondents to update their information on asset holdings in August 2013. For this purpose, we asked them whether they had any type of bank or savings account and/or investments (stocks, bonds, funds, or options). Our outcome variable is a binary index that equals 1 if the respective respondent held any investments, and 0 otherwise. A quarter 
of the households in our sample holds risky assets (cf. Table 1). This is in the range of values reported for the Netherlands from other datasets and earlier periods (Alessie, Hochgürtel, and Soest 2004; Rooij, Lusardi, and Alessie 2011).

Table 1: Descriptive Statistics

\begin{tabular}{|c|c|c|c|c|}
\hline & \multicolumn{2}{|c|}{ Statistic } & \multicolumn{2}{|c|}{ Index } \\
\hline & Mean & Std. Dev. & Model & Meas. Err. \\
\hline Holds risky assets & 0.25 & & & \\
\hline Subjective beliefs: $\mu_{t+1}^{\mathrm{AEX}}-\mu_{t+1}^{\mathrm{sav} .}$ acc. & -1.18 & 8.10 & $\times$ & \\
\hline Subjective beliefs: $\sigma_{t+1}^{\mathrm{AEX}}$ & 6.25 & 4.01 & $\times$ & \\
\hline Risk aversion & 0.00 & 1.00 & $x$ & \\
\hline Absolute difference between belief measures & 11.20 & 13.57 & & $\times$ \\
\hline Lack of confidence in AEX return estimate & 0.54 & 0.23 & & $\times$ \\
\hline Lack of confidence in sav. acc. return estimate & 0.36 & 0.24 & & $\times$ \\
\hline Experimental tasks difficult & 0.49 & 0.33 & & $\times$ \\
\hline Experimental tasks obscure & 0.31 & 0.25 & & $\times$ \\
\hline Financial wealth $\in(10000 €, 30000 €]$ & 0.27 & & $\times$ & $\times$ \\
\hline Financial wealth $\in(30000 €, \infty)$ & 0.27 & & $\times$ & $\times$ \\
\hline Financial wealth missing & 0.17 & & $\times$ & $\times$ \\
\hline Net income $>2500 €$ & 0.46 & & $\times$ & $\times$ \\
\hline Net income missing & 0.07 & & $x$ & $\times$ \\
\hline High education & 0.38 & & $x$ & $x$ \\
\hline $30<$ Age $\leq 50$ & 0.30 & & $x$ & $\times$ \\
\hline $50<$ Age $\leq 65$ & 0.34 & & $x$ & $\times$ \\
\hline Age $>65$ & 0.29 & & $x$ & $\times$ \\
\hline
\end{tabular}

Sources: LISS panel and own calculations. Variables related to the confidence in return estimates, task difficulty, and task obscurity are scaled to range between 0 and 1 . Risk aversion is the standardized average of 3 standardized risk aversion proxies. We omit standard deviations of binary variables. The number of observations is 2,072 .

\subsection{Variables Entering the Economic Model Index}

Subjective Expectations. In August 2013, we asked respondents to describe their expectations about the one-year return of the Amsterdam Exchange Index (AEX). We employed 
a variation of the ball allocation procedure developed by Delavande and Rohwedder (2008), which was explicitly designed for usage in Internet experiments. For each individual, the procedure yields an 8-binned histogram for the expectation of the AEX's one-year return. Using the resulting 7 points on the cumulative distribution function, we follow Hurd, Rooij, and Winter (2011) and fit a log-normal distribution to obtain individual-level measures for $\mu_{t+1}^{\text {risky }}$ and $\sigma_{t+1}^{\text {risky }}$. Because our theoretical framework requires expected excess returns, we also asked respondents for a point estimate for the return of a one-year investment into a standard savings account as the most prevalent safe asset. Section A.1.1 of the Internet Appendix contains detailed descriptions of both procedures.

Recent research in the experimental economics literature has shown that financial incentives induce more truthful reporting of beliefs in tasks like ours (see, for example, Palfrey and Wang 2009; Gächter and Renner 2010; Wang 2011). In order to incentivize subjects, we employed the binarized scoring rule of Hossain and Okui (2013) which is incentive-compatible for a wide range of utility functions. As is common practice with large samples like ours, we randomly selected one in ten subjects for actual payment. The maximum earnings per selected subject were $100 €$ and average earnings equaled $39.66 €$ conditional on being selected for payment in September 2014.

We relegate a detailed presentation of summary statistics of the belief measures to Section A.1.1 of the Internet Appendix and only discuss some notable features at this point. First, our data exhibit the same patterns found previously in the literature, i.e., male, richer, and better educated respondents tend to hold more optimistic expectations (e.g., Manski 2004; Hurd 2009; Hurd, Rooij, and Winter 2011). Second, while our respondents expect a positive AEX return on average, their expectations are rather pessimistic relative to the AEX's historical return distribution. Third, our participants tend to place lower probabilities on extreme returns than what has historically been observed. In contrast, expectations for the return of savings accounts are high relative to the rates actually offered at the time of the survey and on average even exceed the expected return for the AEX. In our empirical analyses, we employ the difference between the expected mean return for the AEX and the expected return for the savings account as the empirical analog of the expected excess return.

Risk Preferences. In September 2013, we elicited risk preferences by asking respondents to complete a variant of the "Preference Survey Module", which was developed in Falk et al. 
(2014) to measure economic preference parameters in large-scale surveys. We further describe it in Section A.1.3 of the Internet Appendix. Respondents first provided a qualitative selfassessment of their willingness to take risks in general and in the financial domain. They then made choices in a series of hypothetical binary lottery tasks. In our main analysis, we employ the average of the three measures' standardized values.

Transaction costs. We include several variables to empirically model the impact of transaction costs on stock market participation decisions. We focus on variables that proxy for variation in transaction costs in the form of either monetary or information costs. If monetary expenses of stock market participation are to some degree fixed - e.g., because banks charge a constant amount for setting up and keeping an investment account - then these costs will be less relevant for wealthy households. We therefore include net household income and financial wealth in the economic index to control for variation in the relevance of monetary transaction costs. If comprehension of the basic functioning of the stock market comes with information costs, then these costs will be lower for more numerate and cognitively able households. Both vary with educational attainment and age (McArdle, Smith, and Willis 2011), which we include as further controls.

\subsection{Variables Entering the Measurement Error Index}

Several quantitative and qualitative measures serve to capture measurement error in individual responses. We employ variables for (i) the consistency with which participants report their expectations, (ii) their confidence in their own beliefs, and (iii) their self-assessment concerning both difficulty and clarity of our survey tasks. On top of such direct proxies, we also include the variables entering transaction costs in the measurement error index. Indeed, it is difficult to argue for exclusion restrictions in one direction or another for education, income, financial wealth, or age.

In September 2013, one month after eliciting the distribution of beliefs, we asked the same set of respondents to provide a point estimate of the one-year return of the AEX. As a quantitative proxy for measurement error, we compute the absolute difference between the response to this question and the mean belief from the ball allocation task. We conjecture that large discrepancies between the two estimates are indicative of measurement error because 
respondents who do not have a stable set of beliefs or are incapable of articulating them meaningfully are likely to provide less consistent estimates. ${ }^{3}$

The first two qualitative proxies for measurement error relate to the confidence respondents have in their own estimates. Following the elicitation of the point estimates for the expected returns of the AEX and the savings account, we asked respondents to use a slider interface to express their confidence in their own belief on a scale from 0 to 10 . We conjecture that respondents with little faith in their own estimates (e.g., because they did not put much cognitive effort into developing their prediction or have not much of an interest in financial matters) provide error-ridden estimates. We invert responses to these questions so that higher values are associated with lower confidence in ones estimates and scale them to the unit interval.

Both in August and September 2013, we asked subjects to use five-point scales to indicate how clear they found the task descriptions and how difficult they considered the belief elicitation itself. We expect that respondents who do not have an elaborate belief distribution find it hard to understand and to complete the tasks. For both questions, we aggregate the responses for August and September to create two further measurement error proxies.

The Internet Appendix provides a more detailed description and further summary statistics of all measurement error proxies. The pairwise correlations between the individual proxies are all positive and range between .08 and .52. Notably, all of the proxies' correlations with sociodemographic variables show the same tendencies. For example, all measurement error proxies tend to be lower for highly educated households or households with higher net income, resembling previously-found patterns regarding inconsistent survey responses or item nonresponse (Manski 2004; Hurd 2009).

\footnotetext{
${ }^{3}$ We are not aware of changes in the economic environment between the two surveys that could have induced people to systematically and substantially revise their beliefs. Between August and September 2013, the AEX varied little with closing prices between 362.93 and 382.58 .
} 


\section{Results}

\subsection{Main Specification}

Table 2 presents parameter estimates for the coefficients of the main specification. In the economic model index, we normalize the coefficient on $\mu_{t+1}^{\mathrm{AEX}}-\mu_{t+1}^{\mathrm{sav}}$ acc. to 1 , thus expressing the remainder of $\beta^{\text {mod }}$ relative to subjective excess return expectations. In the measurement error index, we proceed in the same way with the coefficient on the absolute difference between the belief measures. As we will discuss in detail below, the link function $h(\cdot, \cdot)$ is (close to) monotonically increasing in the economic model index and monotonically decreasing in the measurement error index. This allows us to infer the direction of partial effects from the coefficient estimates.

The coefficients in both indices are estimated with reasonable precision; their signs and relative magnitudes are plausible given the aforementioned shape of the link function and the scaling of the variables (see Table 1). In particular, all variables with exclusion restrictions have the expected signs and most of them are significant. The economic model index increases in the level of the expected excess returns; it decreases in the standard deviation of returns and in risk aversion. The measurement error index increases with all of the 5 employed measurement error proxies.

Both indices vary significantly with a number of the common covariates. For example, financial wealth is positively related to the economic model index and negatively related to the measurement error index. This is consistent with wealthy households facing lower transaction costs, while at the same time having stronger incentives to form an opinion about stock market developments. Interestingly, education seems to mostly work through the measurement error index, but it has little impact on the economic model index.

For presenting the results of semi- and nonparametric methods, it is particularly important to clarify the support of the data, which in our case refers to the two indices. Figure 1 shows a contour plot of the joint density of the estimated indices. We limit the area of Figure 1 and of all subsequent plots to the rectangle spanned by the $5 \%-95 \%$ quantiles of the marginal distributions of both indices. With a correlation coefficient of -0.45 , the indices are characterized by a pronounced negative correlation. Note that this negative correlation 
Table 2: Coefficient estimates for the economic model index and the measurement index

\begin{tabular}{|c|c|c|c|c|}
\hline & \multicolumn{2}{|c|}{ Model } & \multicolumn{2}{|c|}{ Measurement Error } \\
\hline & Estimate & Std. Err. & Estimate & Std. Err. \\
\hline Subjective beliefs: $\mu_{t+1}^{\mathrm{AEX}}-\mu_{t+1}^{\mathrm{sav}}$ acc. & 1.00 & . & . & . \\
\hline Subjective beliefs: $\sigma_{t+1}^{\mathrm{AEX}}$ & -0.70 & 0.36 & . & . \\
\hline Risk aversion & -9.62 & 2.30 & . & $\cdot$ \\
\hline Absolute difference between belief measures & . & . & 1.00 & $\cdot$ \\
\hline Lack of confidence in AEX return estimate & . & . & 44.54 & 24.49 \\
\hline Lack of confidence in sav. acc. return estimate & · & · & 17.09 & 21.43 \\
\hline Experimental tasks difficult & . & · & 37.29 & 16.89 \\
\hline Experimental tasks obscure & . & 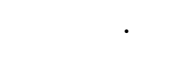 & 30.58 & 18.99 \\
\hline Financial wealth $\in(10000 €, 30000 €]$ & 20.54 & 6.77 & -23.17 & 26.11 \\
\hline Financial wealth $\in(30000 €, \infty)$ & 39.81 & 9.74 & -77.90 & 41.40 \\
\hline Financial wealth missing & 45.29 & 10.57 & -12.78 & 29.30 \\
\hline Net income $>2500 €$ & 8.85 & 3.73 & 22.45 & 11.73 \\
\hline Net income missing & -12.26 & 5.38 & -5.90 & 13.13 \\
\hline High education & 2.24 & 4.00 & -47.84 & 19.50 \\
\hline $30<$ Age $\leq 50$ & 20.34 & 7.87 & 34.20 & 21.52 \\
\hline $50<$ Age $\leq 65$ & 16.42 & 6.51 & 5.32 & 15.21 \\
\hline Age $>65$ & 4.64 & 6.26 & -10.62 & 15.54 \\
\hline
\end{tabular}

Sources: LISS panel and own calculations. The table shows coefficient estimates for the double index binary choice model of Klein and Vella (2009); see Section 2.3 for a detailed description. The dependent variable is a household's stock market participation decision, a binary variable equalling 1 in case the household reports holding any investments, and 0 otherwise. Columns 2 and 3 present estimates of the coefficients and standard errors for the variables contained in the economic model index. Columns 4 and 5 present estimates for the variables contained in the measurement error index.

does not arise purely mechanically due to the previously noted influence of wealth on both indices - in a model that drops all variables common to both indices (described in the next section), we find the same pattern.

The left panel of Figure 2 plots the link function $h(\cdot, \cdot)$, i.e., the predicted probability of stock market participation, for varying levels of the economic model and measurement error indices. Three features of the plot stand out: First, predicted stock market participation rates vary substantially, ranging from single-digit values to more than $70 \%$. Second, participation rates in general vary monotonically in both indices, increasing in the index for the economic model and decreasing in the measurement error index. Third and most importantly, the effects are highly non-linear and interact strongly. In particular, stock market participation is much more 
Figure 1: Joint density of the two indices

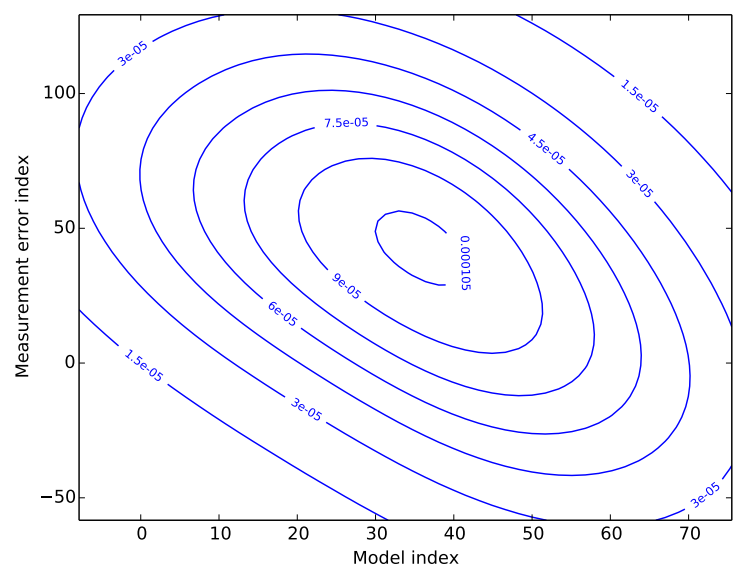

Sources: LISS panel and own calculations. The figure plots the joint density of the estimated indices of the Klein and Vella (2009) model; see Section 2.3 for a detailed description.

responsive to changes in the economic model ingredients at low levels of the measurement error index than at high levels.

Figure 2: Predicted probability to hold risky assets
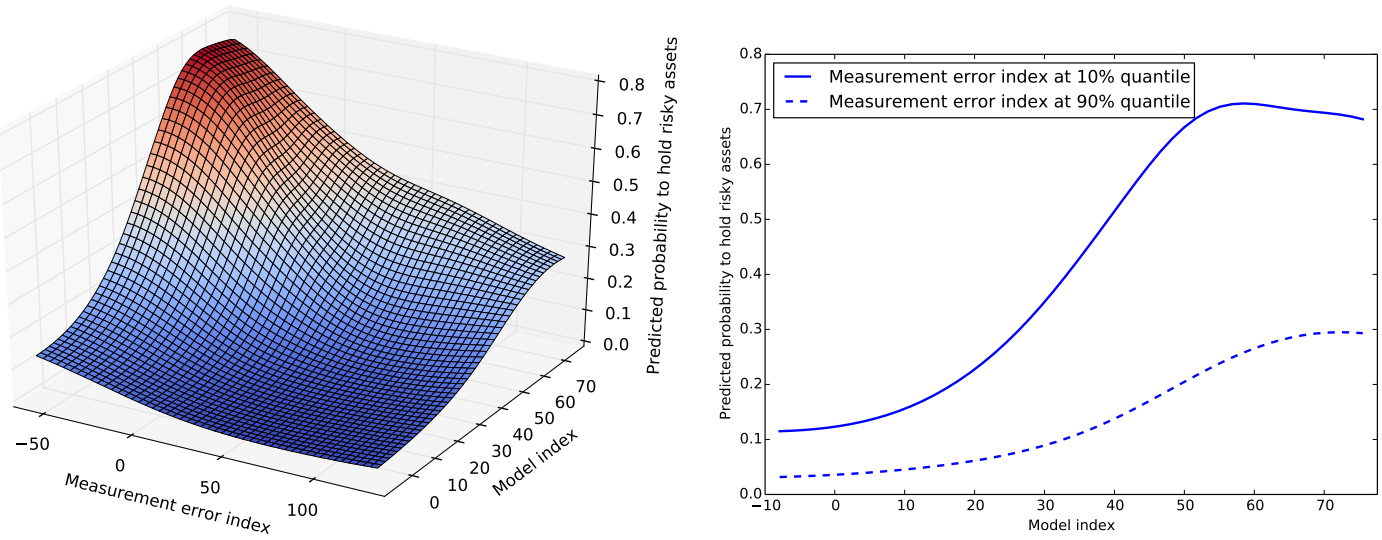

Sources: LISS panel and own calculations. The left panel presents the predicted probability of stock market participation for varying levels of the economic model and measurement error indices. The right panel plots the relation between the predicted probability of participation and the economic model index for the 10 and $90 \%$ quantiles of the measurement error index (-40 and 115). Ranges are limited to the interval between the $5 \%$ and $95 \%$ quantiles of the marginal distributions.

To illustrate the last point more clearly, the second panel in Figure 2 extracts two slices from the first panel. The solid line shows the average response of stock market participation to 
variation in the model index at the $10 \%$-quantile of the measurement error index. There is a pronounced gradient in the middle region, causing predicted risky asset participation to rise from just over $10 \%$ to $70 \%$. The dashed line plots the same relation for the $90 \%$-quantile of measurement error. Again, predicted stock market participation varies in the economic model index as expected, but to a much lesser extent. In particular, even for the highest levels of the economic model index, the predicted probability of participation does not rise above $30 \%$. The discrepancy in shapes of the two lines highlights the importance of measurement error in understanding the relationship between the primitives of economic models and choices.

We calculate average partial effects to quantify the dependence between individual covariates and stock market participation probabilities. In Table 3, we show how changes in covariates affect participation through either the economic or measurement error index. We also show the combined effect that operates through both indices simultaneously. To calculate average partial effects, we increase continuous variables by one standard deviation. For binary variables, we assign individuals in the left-out category a value of 1 .

For the variables solely included in the economic model index, the average partial effects of expected excess return and risk aversion are somewhat larger than the effect of a change in the expected standard deviation of returns. An increase in the expected excess return by one standard deviation is associated with an increase of 3.2 percentage points in the probability to hold investments. Comparable increases in the expected standard deviation and risk aversion reduce the predicted participation rate by 1.2 and 4.1 percentage points, respectively. Increases in either of the measurement error proxies by one standard deviation reduce the propensity to participate by between 0.6 and 2 percentage points. If one thinks of the different indicators in terms of a factor structure (Section A.2 in the Internet Appendix shows that all indicators are positively correlated), varying the underlying factor would likely yield effects of the same order of magnitude as for beliefs or risk aversion.

The effects of financial wealth tend to work through both indices, increasing the propensity to participate in the stock market through the economic model index as well as the measurement error index. In contrast, education seems to affect participation mainly through the measurement error index.

In sum, this section indicates that respondents' beliefs and risk attitudes are indeed predictive of economic choices. However, the extent to which this is the case varies strongly in the 
population. Hence, measurement error in the primitives of the economic model can be used to uncover heterogeneity in its explanatory power.

Table 3: Average partial effects

\begin{tabular}{|c|c|c|c|}
\hline & Model & Meas. Err. & Combined \\
\hline Subjective beliefs: $\mu_{t+1}^{\mathrm{AEX}}-\mu_{t+1}^{\mathrm{sav} .}$ acc. & 0.032 & . & 0.032 \\
\hline Subjective beliefs: $\sigma_{t+1}^{\mathrm{AEX}}$ & -0.012 & . & -0.012 \\
\hline Risk aversion & -0.041 & . & -0.041 \\
\hline Absolute difference between belief measures & $\cdot$ & -0.020 & -0.020 \\
\hline Lack of confidence in AEX return estimate & . & -0.015 & -0.015 \\
\hline Lack of confidence in sav. acc. return estimate & . & -0.006 & -0.006 \\
\hline Experimental tasks difficult & . & -0.019 & -0.019 \\
\hline Experimental tasks obscure & . & -0.011 & -0.011 \\
\hline Financial wealth $\in(10000 €, 30000 €]$ & 0.101 & 0.030 & 0.103 \\
\hline Financial wealth $\in(30000 €, \infty)$ & 0.215 & 0.153 & 0.369 \\
\hline Financial wealth missing & 0.241 & 0.014 & 0.222 \\
\hline Net income $>2500 €$ & 0.038 & -0.034 & 0.003 \\
\hline Net income missing & -0.053 & 0.009 & -0.045 \\
\hline High education & 0.010 & 0.087 & 0.097 \\
\hline $30<$ Age $\leq 50$ & 0.088 & -0.054 & 0.034 \\
\hline $50<$ Age $\leq 65$ & 0.073 & -0.010 & 0.066 \\
\hline Age $>65$ & 0.021 & 0.019 & 0.039 \\
\hline
\end{tabular}

Sources: LISS panel and own calculations. The table presents average partial effects of the Klein and Vella (2009) model; see Section 2.3 for a detailed description. The effects are calculated for a change of 1 standard deviation in continuous variables. For binary variables, we calculate the effect of assigning individuals in the left-out category a value of 1 .

\subsection{Robustness}

To illustrate the robustness of our results to alternative specifications of both the economic model and the measurement error index, we now present an overview of a number of additional analyses. Section B of the Internet Appendix contains all tables, figures, and some additional information. 
No transaction cost proxies. Our main specification includes several covariates that proxy transaction costs. Some of them-financial wealth in particular-have strong effects on stock market participation through both the economic model index and the measurement error index. To investigate whether the predicted interactions between the economic model and measurement error are driven by these sociodemographics only, we estimate one specification without all of the corresponding proxies, i.e., we only include beliefs, risk preferences, and measurement error proxies. Except for lower predicted levels of stock market participation at high values of the model index, the overall results on $h(\cdot, \cdot)$ look very similar. Naturally, the partial effects increase.

Mean beliefs only. In this specification, we restrict the "model index" to consist of expected excess returns only, which gives it an interpretable scale. Section B.2 of the Internet Appendix shows that the gist of our main results is present even in this stripped-down version. The relationship between beliefs and stock market participation is essentially flat at the 90th percentile of the measurement error index, while the probability to hold stocks doubles along the beliefs distribution at the 10th percentile of the measurement error index. This doubling is concentrated around expected excess returns of zero, the relationship is flat at both extremes of the beliefs distributions. The pattern illustrates the usefulness of our semiparametric approach; typical parametric models such as Logit or Probit would yield the steepest gradient to lie at the right tail of the index' support instead of the center.

Additional covariates. We also check the other extreme and employ a "kitchen-sink"-type approach, including binary variables for gender, having children, and being married in both indices along with the variables from our main specification. It turns out, however, that none of these is significantly associated with either the index of the economic model or the measurement error index. In consequence, their inclusion does not affect our results.

Discarding individuals with missing data on financial wealth. In our main specification, we included dummies for financial wealth terciles and for whether information on financial wealth was missing. Since wealth is among the strongest drivers of stock market participation in our model, it is possible that inclusion of respondents with missing information on portfolio value affects our results. To address this concern, we estimate our main specification only with respondents who provided all components of financial wealth. The results are 
very similar. In particular, the shape of $h(\cdot, \cdot)$ is virtually unchanged and the average partial effects of beliefs and preferences are almost identical to those in the main specification.

Alternative belief measure. We showed our main results using stated beliefs over the future development of the Amsterdam Exchange Index (AEX). While it is plausible that expectations over a composite index with high media exposure are a good proxy for "the" risky asset in our model, it is still conceivable that our results are biased due to this specific choice. We therefore elicited the same set of belief variables for the future stock return of Philips N.V., one of the largest publicly traded companies of the Netherlands. As one would expect for a single stock with additional idiosyncratic risk, average partial effects relating to the moments of the belief distribution are reduced by one third (mean) and one half (standard deviation), respectively. The general shape of the link function and all other results are essentially unchanged.

Disaggregated risk aversion measures. By averaging over three distinct variables, we employed a particularly simple aggregation procedure for the risk aversion measure used in our main analysis. When including the three variables separately in the model index, aversion to risk in financial matters emerges as its most important component (Section B.6 of the Internet Appendix). The remainder of our results is not affected.

Alternative ways of calculating the moments of belief distributions. We arrived at our individual-level measures of $\mu_{t+1}^{\mathrm{AEX}}$ and $\sigma_{t+1}^{\mathrm{AEX}}$ by fitting log-normal distributions to respondents' stated cumulative distribution functions. We obtain very similar results when we estimate the moments assuming uniformly distributed expectations within bins (Section B.7 of the Internet Appendix) or when we follow Bellemare, Bissonnette, and Kröger (2012) in approximating each respondent's distribution using a spline interpolation method (Section B.8).

\subsection{Specification with Less Customized Data}

Our analyses employ very detailed data on respondents' stock market expectations based on an incentivized Online Experiment. Our proxies for measurement error include a quantitative variable derived from repeated belief measurements and several qualitative indicators. In many surveys, asking for information this detailed is either impossible or impractical. We now evaluate the applicability of our empirical approach to situations with less customized data. 
In the model index, we replace the mean of the log-normal belief distribution derived from the ball allocation task by individuals' point estimates. We drop the standard deviation of beliefs and use aversion towards risks in general instead of our composite variable (see Section A.1 of the Internet Appendix for a detailed description all measures). In the measurement error index, we only keep the answers to the qualitative questions which asked respondents about the difficulty and obscurity of our survey. We retain all sociodemographic covariates. We then re-run our main analyses using this limited set of variables.

Figure 3: Predicted probability to hold risky assets, specification with less customized data
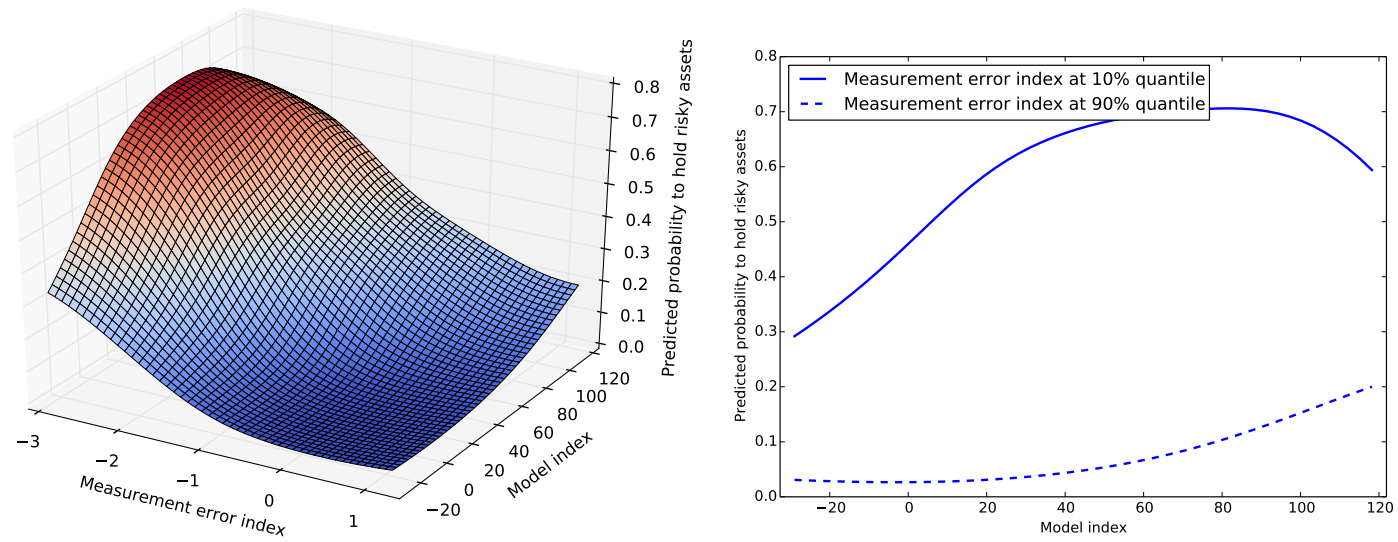

Sources: LISS panel and own calculations. The left panel presents the predicted probability of stock market participation for varying levels of the economic model and measurement error indices. The right panel plots the relation between the predicted probability of participation and the economic model index for the 10 and $90 \%$ quantiles of the measurement error index. These estimations are based on a limited set of variables. Ranges are limited to the interval between the $5 \%$ and $95 \%$ quantiles of the marginal distributions.

Figure 3 illustrates that the main results for this model are broadly similar to those of our main specification. ${ }^{4}$ As the left panel indicates, the predicted probability of holding risky assets strongly varies with both model indices. Importantly, we find strong variation in the gradient of the economic model even with these much coarser data: While the probability of investing in the stock market is sensitive to changes in the economic model index at low values of measurement error, the relationship is essentially flat for high levels of measurement error. The average partial effects in Table 4 again suggest that beliefs and willingness to take risks

\footnotetext{
${ }^{4}$ Section $\mathrm{C}$ of the Internet Appendix provides the full set of figures and tables for this model with reduced data requirements.
} 
positively affect stock market participation, while the measurement error proxies decrease the probability to invest. All magnitudes are roughly similar to our main specification.

Table 4: Average partial effects, specification with less customized data

\begin{tabular}{|c|c|c|c|}
\hline & Model & Meas. Err. & Combined \\
\hline Subjective beliefs (direct question): Log expected excess return & 0.029 & . & 0.029 \\
\hline Aversion to risks in general & -0.028 & . & -0.028 \\
\hline Experimental tasks difficult & · & -0.034 & -0.034 \\
\hline Experimental tasks obscure & . & -0.010 & -0.010 \\
\hline Financial wealth $\in(10000 €, 30000 €]$ & 0.073 & 0.040 & 0.103 \\
\hline Financial wealth $\in(30000 €, \infty)$ & 0.049 & 0.355 & 0.400 \\
\hline Financial wealth missing & 0.088 & 0.117 & 0.205 \\
\hline Net income $>2500 €$ & 0.026 & -0.011 & 0.014 \\
\hline Net income missing & -0.092 & 0.046 & -0.053 \\
\hline High education & -0.001 & 0.117 & 0.116 \\
\hline $30<$ Age $\leq 50$ & 0.091 & -0.079 & 0.014 \\
\hline $50<$ Age $\leq 65$ & 0.054 & 0.013 & 0.070 \\
\hline Age $>65$ & -0.032 & 0.059 & 0.024 \\
\hline
\end{tabular}

Sources: LISS panel and own calculations. The table presents average partial effects of the Klein and Vella (2009) model with a limited number of variables. The effects are calculated for a change of 1 standard deviation in continuous variables. For binary variables, we calculate the effect of assigning individuals in the left-out category a value of 1 .

These results entail two consequences: On the one hand, they suggest that measurement error will also interfere with our understanding of stock market participation decisions when working with simple measures of beliefs and risk preferences. On the other hand, they suggest that our empirical approach to making productive use of measurement error of this kind does not seem to rely on very detailed data to work.

\section{Discussion and Conclusions}

Attempts to measure subjective stock market expectations have dramatically increased over the last two decades. By and large, the results have been encouraging, but obvious signs of poor data quality remain for large fractions of the population regardless of particular survey devices (Manski 2004; Hurd 2009; Kleinjans and Soest 2014). When these measures have been employed to predict portfolio choice behavior (e.g., Hurd and Rohwedder 2011; Hurd, 
Rooij, and Winter 2011; Kézdi and Willis 2011; Hudomiet, Kézdi, and Willis 2011; Huck, Schmidt, and Weizsäcker 2014), significant correlations in the expected direction have emerged. Nevertheless, it seems fair to say that these are not of the magnitude economists might have hoped for. In this paper, we have explored a mechanism that can explain both facts. We have argued that differences in the "propensity to use economic reasoning" may drive heterogeneity in measurement error and explain why the empirical content of portfolio choice models has been moderate on average.

While the idea of heterogeneous decision rules is certainly not new (e.g., Ameriks and Zeldes 2004; Kahneman 2011; Binswanger and Salm 2013, among many others), we are the first to suggest that the magnitude of measurement error in subjective expectations data can be used to uncover such heterogeneity. To explore this link empirically, we have used a semiparametric double index model due to Klein and Vella (2009) on a dataset specifically collected for this purpose. Our results show that stock market participation reacts much more strongly to the primitives of an economic model (preferences, beliefs, and transaction costs) for low values of the measurement error index than for high values. This pattern obtains in a wide variety of specification choices, including a setting where we restrict ourselves to variables that are available in many datasets.

Two pieces of evidence lend further support to our interpretation of these patterns. First, if we were dealing with classical measurement error in beliefs, taking averages of multiple measurements with uncorrelated idiosyncratic variation should increase the predictive power of expectations. A simple exercise shows that such a pattern does not obtain in our data. We run OLS regressions of stock market participation on convex combinations of our two belief measures (the results are unchanged if we add controls). In Section D of the Internet Appendix, we show that the maximum $R^{2}$ is reached close to the point where all the weight is on the mean from ball allocation task. Hence, adding the second measure hardly helps at all. Second, stock market participation was lower for high values of the measurement error index in all our specifications. This pattern suggests that measurement error does not arise purely because of differential effort put into the subjective belief tasks. If some subjects gave random answers which were uncorrelated with portfolio allocations, participation rates should be the same on average. This suggests that the patterns we found do not merely reflect attenuation bias due to respondents' carelessness in providing subjective data. 
Our method is applicable to a wide range of settings where subjective data is used. For example, we noted above that the precision of individual-level risk preference parameters obtained from experiments via revealed-preference paradigms varies tremendously in heterogeneous populations (Gaudecker, Soest, and Wengström 2011; Choi et al. 2014). These findings strongly suggest that the degree to which meaningful structural parameters of economic models exist (Rust 2014) varies across individuals. We have shown how the individual-level measurement error in structural parameters can be used when these parameters are employed to explain economically interesting outcomes. Doing so should help dampen the hostility of economists to subjective data (Manski 2004) that has arisen largely because of perceived data quality. We have turned this argument around and shown that once there is direct information on measurement error at the individual level, it can be used to learn about the economic mechanism of interest.

\section{References}

Alessie, Rob, Stefan Hochgürtel, and Arthur van Soest (2004). "Ownership of Stocks and Mutual Funds: A Panel Data Analysis". In: Review of Economics and Statistics 86.3, pp. 783-796.

Ameriks, John and Stephen P. Zeldes (2004). "How Do Household Portfolio Shares Vary with Age?" Mimeo, Columbia Graduate School of Business.

Bellemare, Charles, Luc Bissonnette, and Sabine Kröger (2012). "Flexible Approximation of Subjective Expectations Using Probability Questions". In: Journal of Business $\&$ Economic Statistics 30.1, pp. 125-131.

Binswanger, Johannes and Martin Salm (2013). "Does Everyone Use Probabilities? Intuitive and Rational Decisions about Stockholding". IZA Discussion Paper 7265.

Bruine de Bruin, Wändi and Katherine G. Carman (2012). "Measuring Risk Perceptions: What Does the Excessive Use of 50\% Mean?" In: Medical Decision Making 32.2, pp. 232-236.

Bruine de Bruin, Wändi, Baruch Fischhoff, Susan G. Millstein, and Bonnie L. Halpern-Felsher (2000). "Verbal and Numerical Expressions of Probability: "it's a Fifty-fifty Chance"”. In: Organizational Behavior and Human Decision Processes 81.1, pp. 115-131.

Campbell, John Y. and Luis M. Viceira (2002). Strategic Asset Allocation. Clarendon Lectures in Economics. Oxford University Press. 
Choi, Syngjoo, Shachar Kariv, Wieland Müller, and Dan Silverman (2014). "Who is (More) Rational?" In: American Economic Review 104.6, pp. 1518-1550.

Delavande, Adeline and Susann Rohwedder (2008). "Eliciting Subjective Probabilities in Internet Surveys". In: Public Opinion Quarterly 72.5, pp. 866-891.

Falk, Armin, Anke Becker, Thomas Dohmen, David Huffman, and Uwe Sunde (2014). "An Experimentally Validated Preference Survey Module". Mimeo, Universität Bonn.

Gächter, Simon and Elke Renner (2010). "The Effects of (Incentivized) Belief Elicitation in Public Goods Experiments". In: Experimental Economics 13, pp. 364-377.

Gaudecker, Hans-Martin von (forthcoming). "How Does Household Portfolio Diversification Vary with Financial Sophistication and Financial Advice?" In: Journal of Finance.

Gaudecker, Hans-Martin von, Arthur van Soest, and Erik Wengström (2011). "Heterogeneity in Risky Choice Behaviour in a Broad Population". In: American Economic Review 101.2, pp. 664-694.

Haliassos, Michael and Carol C. Bertaut (1995). "Why Do so Few Hold Stocks?" In: Economic Journal 105.432, pp. 1110-1129.

Hoderlein, Stefan and Joachim Winter (2010). "Structural Measurement Errors in Nonseparable Models". In: Journal of Econometrics 157.2, pp. 432-440.

Hossain, Tanjim and Ryo Okui (2013). "The Binarized Scoring Rule". In: Review of Economic Studies 80.3, pp. 984-1001.

Huck, Steffen, Tobias Schmidt, and Georg Weizsäcker (2014). "The Standard Portfolio Choice Problem in Germany". Mimeo, Humboldt Universität Berlin. Available at http://dx.doi . org/10.2139/ssrn. 2432045 .

Hudomiet, Péter, Gábor Kézdi, and Robert J. Willis (2011). "Stock Market Crash and Expectations of American Households". In: Journal of Applied Econometrics 26.3, pp. 393415 .

Hurd, Michael D. (2009). "Subjective Probabilities in Household Surveys". In: Annual Review of Economics 1.1, pp. 543-562.

Hurd, Michael D. and Susann Rohwedder (2011). "Stock Price Expectations and Stock Trading". RAND Labor and Population Working Paper 938.

Hurd, Michael D., Maarten C. J. van Rooij, and Joachim Winter (2011). "Stock Market Expectations of Dutch Households". In: Journal of Applied Econometrics 26.3, pp. 416436. 
Kahneman, Daniel (2011). Thinking, Fast and Slow. New York, NY: Farrar, Straus and Giroux.

Kézdi, Gábor and Robert J. Willis (2011). "Household Stock Market Beliefs and Learning". NBER Working Paper 17614.

Klein, Roger W. and Richard H. Spady (1993). "An Efficient Semiparametric Estimator for Binary Response Models". In: Econometrica 61.2, pp. 387-421.

Klein, Roger W. and Francis Vella (2009). "A Semiparametric Model for Binary Response and Continuous Outcomes under Index Heteroscedasticity". In: Journal of Applied Econometrics 24.5 , pp. $735-762$.

Kleinjans, Kristin J. and Arthur van Soest (2014). "Rounding, Focal Point Answers and Nonresponse to Subjective Probability Questions". In: Journal of Applied Econometrics 29.4, pp. 567-585.

Manski, Charles F. (2004). "Measuring Expectations". In: Econometrica 72.5, pp. 1329-1376.

Maurer, Jürgen (2009). "Who Has a Clue to Preventing the Flu? Unravelling Supply and Demand Effects on the Take-up of Influenza Vaccinations". In: Journal of Health Economics 28.3, pp. 704-717.

Maurer, Jürgen, Roger W. Klein, and Francis Vella (2010). "Subjective Health Assessments and Active Labor Market Participation of Older Men: Evidence from a Semiparametric Binary Choice Model with Nonadditive Correlated Individual-specific Effects". In: Review of Economics and Statistics 93.3, pp. 764-774.

McArdle, John J., James P. Smith, and Robert J. Willis (2011). "Cognition and Economic Outcomes in the Health and Retirement Survey". In: Explorations in the Economics of Aging. Ed. by David A. Wise. University of Chicago Press. Chap. 7, pp. 209-233.

Palfrey, Thomas R. and Stephanie W. Wang (2009). "On Eliciting Beliefs in Strategic Games". In: Journal of Economic Behavior $\&$ Organization 71.2, pp. 98-109.

Rabin, Matthew (2000). "Risk Aversion and Expected Utility Theory: A Calibration Theorem". In: Econometrica 68.5, pp. 1281-1292.

Rooij, Maarten C. J. van, Annamaria Lusardi, and Rob Alessie (2011). "Financial Literacy and Stock Market Participation". In: Journal of Financial Economics 101.2, pp. 449-472.

Rust, John (2014). "The Limits of Inference with Theory: A Review of Wolpin (2013)". In: Journal of Economic Literature 52.3, pp. 820-850.

Schennach, Susanne M. (2013). "Measurement Error in Nonlinear Models - A Review". In: Advances in Economics and Econometrics. Ed. by Daron Acemoglu, Manuel Arellano, and 
Eddie Dekel. Vol. 3. Econometric Society Monographs 51. Cambridge University Press. Chap. 8, pp. 296-337.

Stiglitz, Joseph E. (2002). "Information and the Change in the Paradigm in Economics". In: American Economic Review 92.3, pp. 460-501.

Vissing-Jørgensen, Annette (2002). "Towards an Explanation of Household Portfolio Choice Heterogeneity: Nonfinancial Income and Participation Cost Structures". NBER Working Paper 8884.

Wang, Stephanie W. (2011). "Incentive Effects: The Case of Belief Elicitation from Individuals in Groups". In: Economics Letters 111.1, pp. 30-33.

Wansbeek, Tom J. and Erik Meijer (2000). Measurement Error and Latent Variables in Econometrics. Amsterdam: Elsevier North Holland. 